\title{
Bioinspired Multivalent Ion Responsive Nanopore with Ultrahigh Ion Current Rectification
}

\author{
SUPPORTING INFORMATION
}

Zhong-Qiu Li, Yang Wang, Zeng-Qiang Wu, *Ming-Yang Wu, Xing-Hua Xia*

State Key Laboratory of Analytical Chemistry for Life Science, School of

Chemistry and Chemical Engineering, Nanjing University, Nanjing 210023,

China

Note 1. Characterization of PC nanopores

Note 2. Charge inversion inside the conical nanopore

Note 3. Total junction potentials across the membrane under different electrolyte conditions

Note 4. Influence of $\mathrm{Fe}^{3+}-\mathrm{Fe}(\mathrm{CN})_{6}{ }^{3-}$ combination

Note 5. Adsorption of $\mathrm{Fe}^{3+}$ induces charge inversion inside the hourglass nanopore

Note 6. Ion transport properties of the hourglass nanopore with ultra-small tip diameter

Note 7. Numerical simulation for ionic transport properties of hourglass nanopores 


\section{Note 1. Characterization of PC nanopores}

The conical and hourglass nanopores were fabricated by asymmetric and symmetric chemical etching of polycarbonate (PC) membranes according to a previously reported method $^{[1]}$. Figure S1 shows the SEM images of the base of a conical nanopore, hourglass nanopore with a small tip (PC-s), and hourglass nanopore with a large tip (PC-1). The base diameters $\left(d_{\text {base }}\right)$ of these nanopores are listed in Table S1. The diameters of the tip $\left(d_{\text {tip }}\right)$ of all these three nanopores were estimated by an electrochemical method ${ }^{[2]}$ and $d_{\text {tip }}$ was calculated by the following equation:

$$
\mathrm{d}_{\mathrm{tip}}=\frac{4 \mathrm{lI}}{\pi \mathrm{kUD}}
$$

Here, $l$ is the length of the nanopore, which is $12 \mu \mathrm{m}$ in our work; $I$ is the transmembrane current; $U$ is the transmembrane voltage; $D$ is the base diameter of the nanopore; $k$ is the conductivity of the electrolyte solution. If a $1 \mathrm{M} \mathrm{KCl}$ solution is used in our experiment, the conductivity $(k)$ is $11.17 \Omega^{-1} \mathrm{~m}^{-1}$ at $25^{\circ} \mathrm{C}$. The calculated $\mathrm{d}_{\text {tip }}$ is also listed in Table $\mathbf{S 1}$.
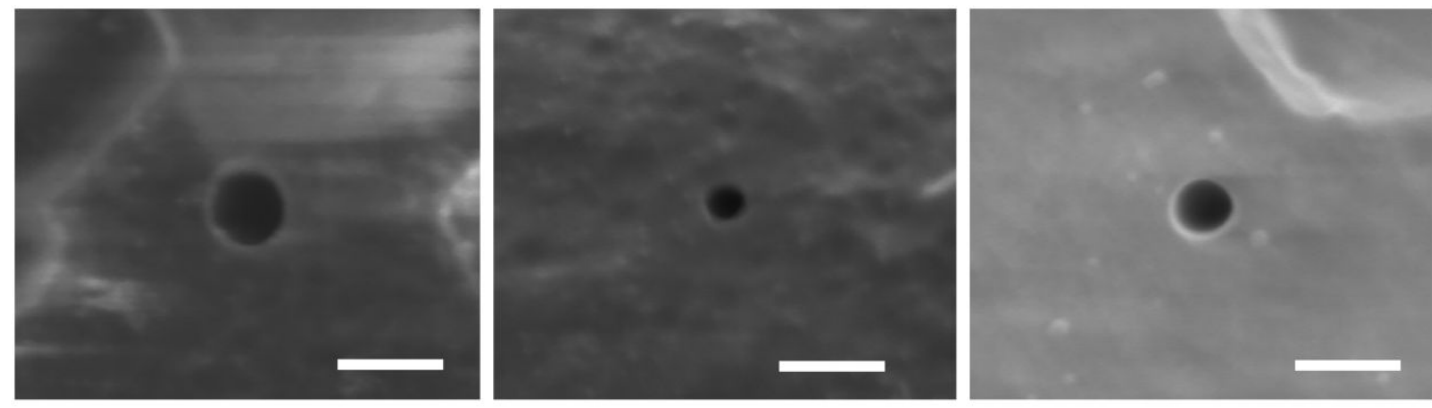

Figure S1. SEM characterization of nanopore. SEM images of the base of (a) conical nanopore, (b) hourglass nanopore with small tip (PC-s), and (c) hourglass nanopore with large tip (PC-1). The scale bar is $500 \mathrm{~nm}$. 
Table S1. Base and Tip Diameters of The Conical and Hourglass Nanopores, Respectively

\begin{tabular}{llllll}
\hline & $\begin{array}{l}\text { Conical } \\
\text { nanopore }\end{array}$ & $\begin{array}{l}\text { Hourglass } \\
(\mathrm{PC}-\mathrm{s})\end{array}$ & nanopore & $\begin{array}{l}\text { Hourglass } \\
(\mathrm{PC}-1)\end{array}$ & nanopore \\
\hline$d_{\text {base }}(\mathrm{nm})$ & 378 & 208 & 302 & \\
$d_{\text {tip }}(\mathrm{nm})$ & 0.46 & 0.91 & 7.8 & \\
\hline
\end{tabular}

\section{Note 2. Charge inversion inside the conical nanopore}

To confirm the charge inversion on PC materials surface, we investigated the ion transport property of a conical nanopore. The current-voltage (IV) curves of this nanopore were measured in $\mathrm{KCl}$ and $\mathrm{FeCl}_{3}$ solutions, respectively (Figure S2a and b). In $\mathrm{KCl}$ solution, larger currents occur at positive voltages; however, larger currents are observed at negative voltages in $\mathrm{FeCl}_{3}$ solution, showing a reversed ICR effect. It demonstrates that the surface charge is reversed by $\mathrm{Fe}^{3+}$ ion adsorption.
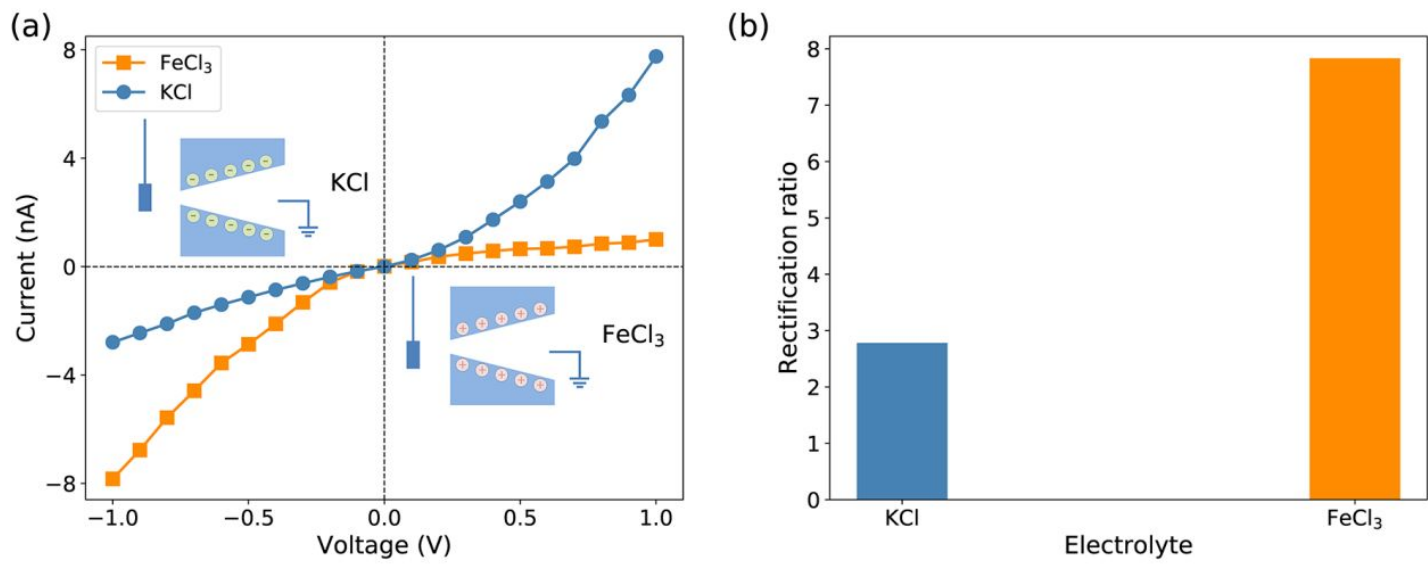

Figure S2. Ion transport property in a conical nanopore. (a) IV curves of a conical nanopore in $0.1 \mathrm{M} \mathrm{KCl}$ and $10 \mathrm{mM} \mathrm{FeCl}_{3}$ solutions. (b) Calculated ICR ratios from the IV curves. 
Note 3. Total junction potentials across the membrane under different electrolyte conditions

When putting a $\mathrm{Ag} / \mathrm{AgCl}$ electrode inside an electrolyte solution, a junction potential is formed between the electrode and the solution. In our work, two different electrolyte solutions were placed separately at two sides of the membrane. Therefore, the junction potential was different on both sides of the membrane, resulting in a total junction potential across the membrane. Here, the junction potentials were calculated according to Goldman's assumption ${ }^{[3]}$, and bulk values of diffusion coefficients of the ions were used in the calculation. As can be seen from Table S2, the total junction potential did not exceed $21 \mathrm{mV}$. Since a large range of voltages $(-1 \mathrm{~V}$ to $+1 \mathrm{~V})$ were adopted in the study, the junction potentials were not considered here.

Table S2. Total Junction Potentials across The Membrane under Different Electrolyte Conditions

\begin{tabular}{lll}
\hline $\begin{array}{l}\text { Electrolyte }(10 \mathrm{mM}) \text { on one } \\
\text { side of the membrane }\end{array}$ & $\begin{array}{l}\text { Electrolyte }(10 \mathrm{mM}) \text { on the } \\
\text { other side of the membrane }\end{array}$ & $\begin{array}{l}\text { Absolute value of the tot: } \\
\text { junction potential }(\mathrm{mV})\end{array}$ \\
\hline $\mathrm{NaCl}$ & $\mathrm{KCl}$ & 21 \\
$\mathrm{LiCl}$ & $\mathrm{KCl}$ & 19 \\
$\mathrm{MgCl}_{2}$ & $\mathrm{~K}_{2} \mathrm{SO}_{4}$ & 11 \\
$\mathrm{CaCl}_{2}$ & $\mathrm{~K}_{2} \mathrm{SO}_{4}$ & 12 \\
$\mathrm{FeCl}_{3}$ & $\mathrm{~K}_{3} \mathrm{Fe}(\mathrm{CN})_{6}$ & 9 \\
$\mathrm{LaCl}_{3}$ & $\mathrm{~K}_{3} \mathrm{Fe}(\mathrm{CN})_{6}$ & 9 \\
\hline
\end{tabular}




\section{Note 4. Influence of $\mathrm{Fe}^{3+}-\mathrm{Fe}(\mathrm{CN})_{6}{ }^{3-}$ combination}

As one knows, $\mathrm{Fe}^{3+}$ can react with $\mathrm{Fe}(\mathrm{CN})_{6}{ }^{4-}$ to form Prussian blue. Therefore, $\mathrm{Fe}^{3+}$, $\mathrm{Fe}(\mathrm{CN})_{6}{ }^{3-}$ and certain reducing specie in the solution might react to form particles inside the nanopore and affect the ion transport. To address this problem, we separately added $\mathrm{FeCl}_{3}$ and $\mathrm{K}_{3} \mathrm{Fe}(\mathrm{CN})_{6}$ into the two sides of an anodic aluminum oxide (AAO) membrane (through-hole, $200 \mathrm{~nm}$ in diameter, from Whatman), and the cross-section of the membrane before and after applying an trans-membrane voltage $(+1 \mathrm{~V}$, working electrode at $\mathrm{K}_{3} \mathrm{Fe}(\mathrm{CN})_{6}$ side) for 5 min was monitored. As the result shows (Figure S3), no particles are found inside the nanopore after the experiment, which means that we can rule out the possible formation of deposits from the $\mathrm{Fe}^{3+}-\mathrm{Fe}(\mathrm{CN})_{6}{ }^{3-}$ combination.
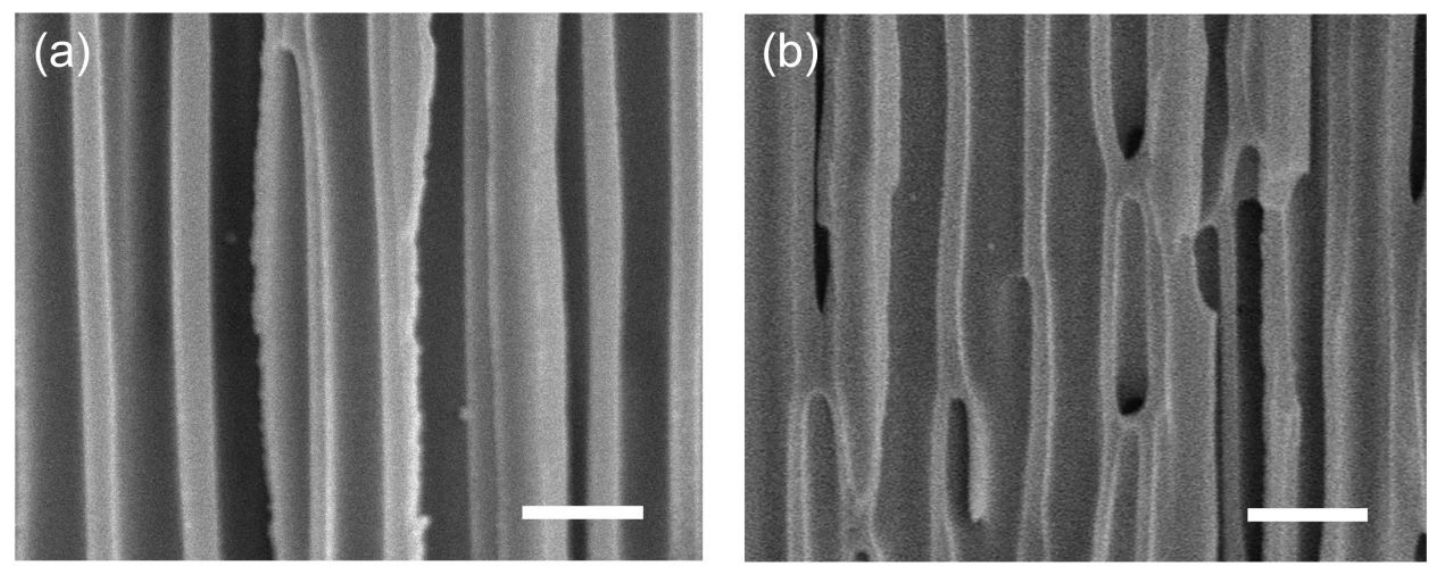

Figure S3. SEM characterization of AAO membrane before and after experiment.

SEM images of the cross-section of AAO membranes (a) before and (b) after ion transport experiment. The scale bar is $500 \mathrm{~nm}$. 
Note 5. Adsorption of $\mathrm{Fe}^{3+}$ induces charge inversion inside the hourglass nanopore In order to further investigate the charge inversion process inside the hourglass nanopore, we measured the IV curves at different times after adding $\mathrm{FeCl}_{3} / \mathrm{K}_{3} \mathrm{Fe}(\mathrm{CN})_{6}$ $(10 \mathrm{mM})$. As can be seen from Figure $\mathbf{S 4}$, the ICR ratio gradually increases and then reaches a plateau. It indicates that the adsorption of $\mathrm{Fe}^{3+}$ attains the equilibrium state at around $20 \mathrm{~min}$. The ICR ratio is smaller than the one described in the manuscript because the hourglass nanopore used here has a larger tip diameter.
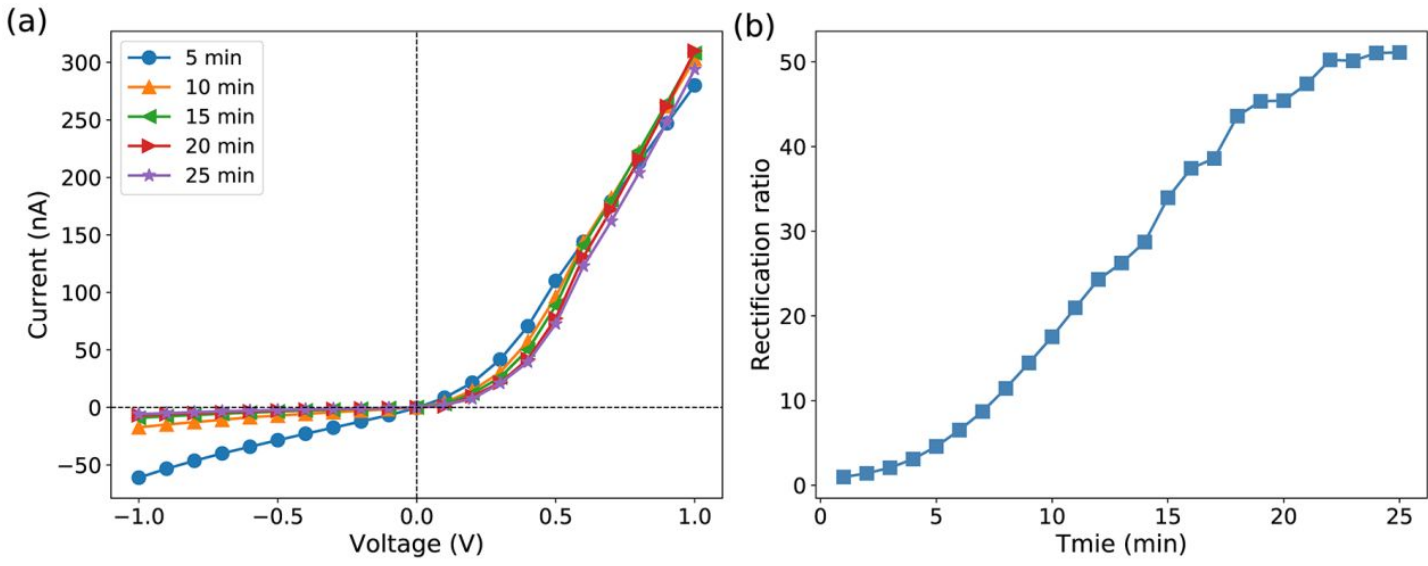

Figure S4. Adsorption of $\mathrm{Fe}^{3+}$ on nanopore surface. (a) IV curves of the hourglass nanopore at different times after adding $\mathrm{FeCl}_{3} / \mathrm{K}_{3} \mathrm{Fe}(\mathrm{CN})_{6}$. The concentration of $\mathrm{FeCl}_{3}$ and $\mathrm{K}_{3} \mathrm{Fe}(\mathrm{CN})_{6}$ was $10 \mathrm{mM}$. (b) Calculated ICR ratios versus time of the hourglass nanopore. 
Note 6. Ion transport properties of the hourglass nanopore with ultra-small tip diameter

The diameter of small tips has a great influence on the ICR property of the hourglass nanopore. The smaller tip diameter is, the higher the ICR ratio can be obtained. We conducted a control experiment to monitor the ion $\left(\mathrm{Ca}^{2+}\right)$ diffusion process at the small tip (main manuscript, "EXPERIMENTAL SECTION”) using fluorescent signal as illustrated by Figure S5. We fabricated an hourglass nanopore with ultra-small tip $(<1$ $\mathrm{nm}, \mathrm{PC}-\mathrm{us}$, the diameter is too small to estimate). As the current-voltage curve shows (Figure S6), the "off" current can hardly be measured since it approaches the detection limit of the picoammeter. The ICR ratio is calculated to be $\sim 850$, which, as we know, is larger than most reported bipolar nanofluidic diodes.

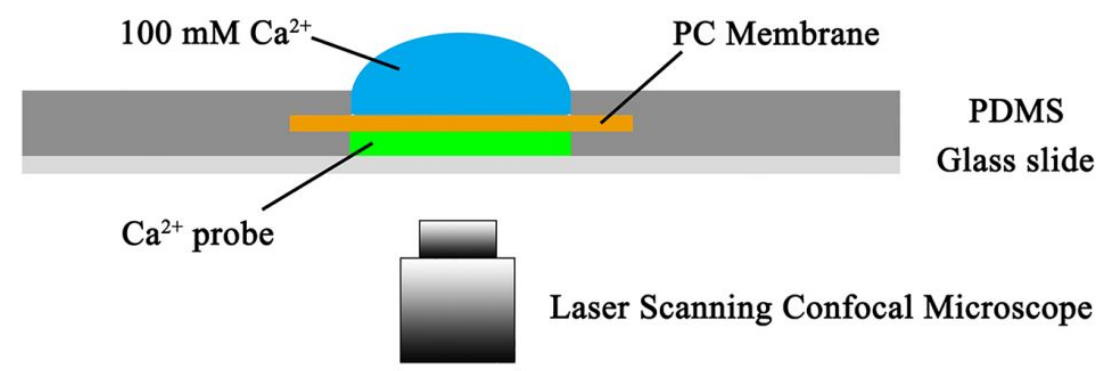


Figure S5. Setup for the fluorescent experiment.
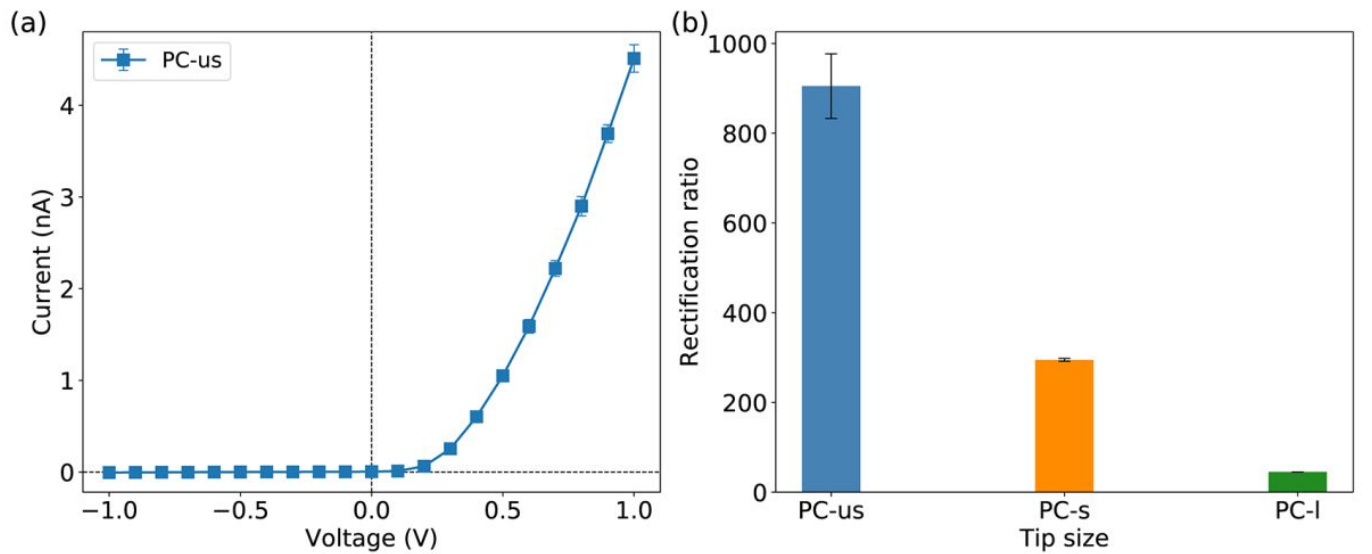

Figure S6. Ion transport in hourglass nanopore with ultra-small tip. (a) IV curves of the hourglass nanopore (with tip diameter of $<1 \mathrm{~nm}$ ) with $10 \mathrm{mM} \mathrm{FeCl}_{3} / \mathrm{K}_{3} \mathrm{Fe}(\mathrm{CN})_{6}$.

(b) ICR ratios of hourglass nanopores with different tip diameters. 


\section{Note 7. Numerical simulation for ionic transport properties of hourglass}

\section{nanopores}

We used finite element method (FEM) to study the mechanism of ion transport in hourglass nanopores with the combination of the Poisson-Nernst-Planck (PNP) equation (eq. s2 and eq. s3).

$\nabla^{2} \Phi=-\frac{\mathrm{F}}{\varepsilon} \sum_{\mathrm{I}} \mathrm{z}_{\mathrm{i}} \mathrm{c}_{\mathrm{i}}$

$\mathrm{J}_{\mathrm{i}}=-\mathrm{D}_{\mathrm{i}} \nabla \mathrm{c}_{\mathrm{i}}-\frac{\mathrm{z}_{\mathrm{i}} \mathrm{F}}{\mathrm{RT}} \mathrm{D}_{\mathrm{i}} \mathrm{c}_{\mathrm{i}} \nabla \Phi$

where, $J_{i}, D_{i}, c_{i}$, and $z_{i}$ are the flux, the diffusion coefficient, the concentration, and the charge of species $i$, respectively; $\Phi$ is the electrical potential; $\varepsilon$ is the dielectric constant of fluid; $F, R$ and $T$ are the Faraday constant, the ideal gas constant and the Kelvin temperature, respectively. A 2 dimensional axis symmetric model was established and the computed domain of the hourglass nanopore is described in Figure S7. The total length of the nanopore was set as $2000 \mathrm{~nm}$ and the base diameter was set as $200 \mathrm{~nm}$. The tip diameter was set according to the experiment condition. For the study of $\mathrm{Fe}^{3+}$ diffusion in the nanopore, tip diameter was set as $1 \mathrm{~nm}$ (for PC-s) and $8 \mathrm{~nm}$ (for PC-1); while, for the study of ICR mechanism, it was kept as $1 \mathrm{~nm}$. The detailed information about the boundary conditions is listed in Table S3. The value of surface charge is dependent on the type and concentration of the salt. The detailed information about boundary conditions under different solutions is listed in Table S4. Different types of electrolyte solutions $(10 \mathrm{mM})$ were utilized in the model, therefore, the diffusion coefficients were set according to the types of the ions (Table S4) 


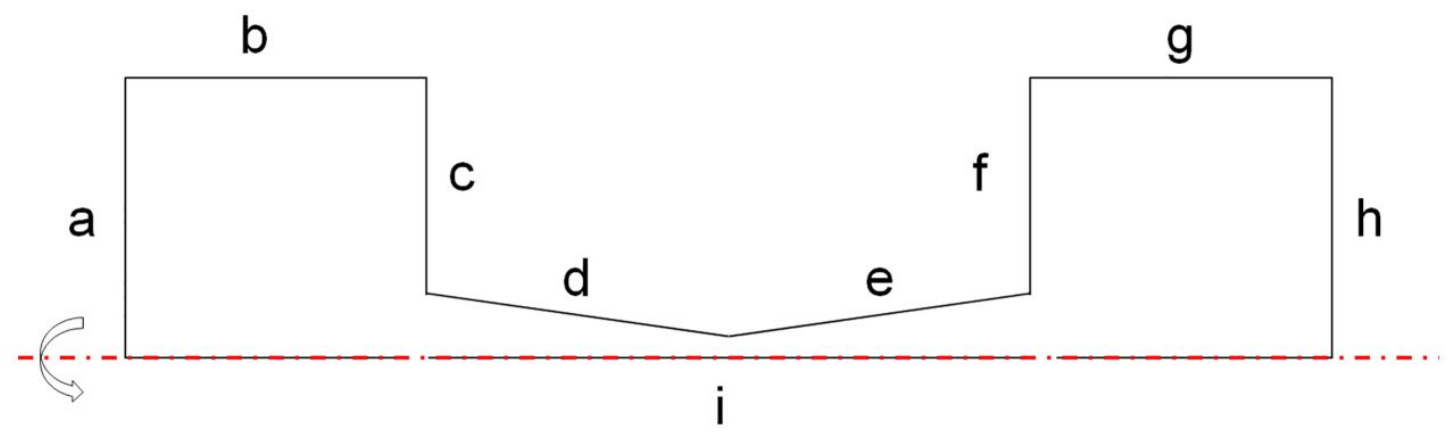

Figure S7. Computed domain of the hourglass nanopore.

Table S3. Boundary Conditions of the Axis Symmetry Models

\begin{tabular}{lll}
\hline Boundary & Poisson equation(eq. s1) & Nernst-Planck equation (eq. s2) \\
\hline $\mathrm{a}$ & $\Phi=V$ & $c_{1}, c_{2}, c_{3}, c_{4}$ \\
$\mathrm{~h}$ & $\Phi=0$ & $c_{1}, c_{2}, c_{3}, c_{4}$ \\
$\mathrm{~b}, \mathrm{c}, \mathrm{f}, \mathrm{g}$ & $n \cdot \nabla \Phi=0$ & $n \cdot J_{i}=0$ \\
$\mathrm{~d}$ & $n \cdot \nabla \Phi=\sigma_{1}$ & $n \cdot J_{i}=0$ \\
$\mathrm{e}$ & $n \cdot \nabla \Phi=\sigma_{2}$ & $n \cdot J_{i}=0$ \\
$\mathrm{i}$ & axis symmetry & axis symmetry \\
\hline
\end{tabular}

Table S4. Boundary Settings of a, $h, d$, e under Different Electrolyte Conditions

\begin{tabular}{llllll}
\hline & $\begin{array}{l}\mathrm{a} \\
(\mathrm{mM})\end{array}$ & $\begin{array}{l}\mathrm{h} \\
(\mathrm{mM})\end{array}$ & $\begin{array}{l}\mathrm{d} \\
\left(\mathrm{mC} / \mathrm{m}^{2}\right)\end{array}$ & $\begin{array}{l}\mathrm{e} \\
\left(\mathrm{mC} / \mathrm{m}^{2}\right)\end{array}$ & $\begin{array}{l}\text { Diffusion coefficient } \\
\left(\mathrm{m}^{2} / \mathrm{s}\right)\end{array}$ \\
\hline $\mathrm{Na}^{+}, \mathrm{Cl}^{-}$ & $c_{1}=10, c_{2}$ & $c_{1}=0, c_{2}$ & -10 & -10 & $D_{1}=1.198 \mathrm{e}-9$ \\
$/ \mathrm{K}^{+}, \mathrm{Cl}^{-}$ & $=10, c_{3}$ & $=0, c_{3}$ & & & $\begin{array}{l}D_{2}=2.032 \mathrm{e}-9 \\
D_{3}=1.957 \mathrm{e}-9\end{array}$ \\
& $=0$, & $=10, c_{4}$ & & & $D_{4}=2.032 \mathrm{e}-9$ \\
\hline $\mathrm{Mg}^{2+}, \mathrm{Cl}^{-}$ & $c_{4}=0$ & $=10$ & & & $D_{1}=1.572 \mathrm{e}-9$ \\
$/ \mathrm{K}^{+}, \mathrm{SO}_{4}{ }^{2-}$ & $c_{1}=10, c_{2}$ & $c_{1}=0, c_{2}$ & 0 & -10 & $D_{2}=2.032 \mathrm{e}-9$ \\
& $=20, c_{3}$ & $=0, c_{3}$ & & & $D_{3}=1.957 \mathrm{e}-9$ \\
& $=0$, & $=20, c_{4}$ & & & $D_{4}=2.13 \mathrm{e}-9$ \\
\hline $\mathrm{Fe}^{3+}, \mathrm{Cl}-$ & $c_{4}=0$ & $=10$ & & & $D_{1}=1.853 \mathrm{e}-9$ \\
$/ \mathrm{K}^{+}, \mathrm{Fe}(\mathrm{CN})_{6}{ }^{3-}$ & $=30, c_{3}=10, c_{2}$ & $c_{1}=0, c_{2}$ & +10 & -10 & $D_{2}=2.032 \mathrm{e}-9$ \\
& $=0$, & $=30, c_{3}$ & & & $D_{3}=1.957 \mathrm{e}-9$ \\
& $c_{4}=0$ & $=10$ & & & $D_{4}=2.687 \mathrm{e}-9$ \\
\hline
\end{tabular}




\section{REFERENCES}

[1] C. C. Harrell, Y. Choi, L. P. Horne, L. A. Baker, Z. S. Siwy, C. R. Martin, Langmuir 2006, 22, 10837.

[2] a) Q. Liu, K. Xiao, L. Wen, H. Lu, Y. Liu, X.-Y. Kong, G. Xie, Z. Zhang, Z. Bo, L. Jiang, J. Am. Chem. Soc. 2015, 137, 11976; b) Y. Xie, X. Wang, J. Xue, K. Jin, L. Chen, Y. Wang, Appl. Phys. Lett. 2008, 93.

[3] A. Alcaraz, E. M. Nestorovich, M. Aguilella-Arzo, V. M. Aguilella, S. M. Bezrukov, Biophys. J. 2004, 87, 943. 